\title{
CLINICAL PHARMACY IN GALLE SRI LANKA, COLLABORATION AND FRIENDSHIP
}

\author{
HANA MORRISSEY ${ }^{1}$, SHUKRY ZAWAHIR ${ }^{2}$, SUJEEWA HETTIHEWA ${ }^{2}$, PATRICK BALL ${ }^{1}$
}

1School of Pharmacy, Faculty of Science and Engineering, University of Wolverhampton, United Kingdom, ${ }^{2}$ Faculty of Pharmacy, The University of Sydney, NSW Australia, Faculty of Medicine, Ruhuna University, Galle, Sri Lanka

Email: hana.morrissey@wlv.ac.uk

Received: 05 Feb 2017 Revised and Accepted: 18 Apr 2017

\begin{abstract}
Pharmacy undergraduate courses in Ruhuna, while is more practice focus than many of the other courses in Sri Lanka, it is still missing clinical pharmacy elements. Collaboration between academic staff from Ruhuna University and two international clinical pharmacy academics was established in 2014. The aim of this paper is to report on a clinical pharmacy training program, delivered by the international academics and supported by the Sri Lankan academics to pharmacy students in 2015-2016. After short conceptualization lecture on each topic, there was a workshop which was structured as team case-based learning progressive case studies. Topics included mental health, pharmacokinetics, interpreting laboratory results, parenteral drug compatibility, special hospital compounding and medication review, of which all were assessed in the final examination. A student found the team based learning to be engaging and enabled them to independently and critically think in a safe environment and preferable over the traditional lectures.
\end{abstract}

Keywords: Clinical Pharmacy, Medication review, Undergraduate pharmacy students, International teaching collaboration, Train the trainer

(C) 2017 The Authors. Published by Innovare Academic Sciences Pvt Ltd. This is an open access article under the CC BY license (http://creativecommons.org/licenses/by/4.0/) DOI: http://dx.doi.org/10.22159/ajpcr.2017v10s3.21354

\section{INTRODUCTION}

Pharmacy practice has always been and remains an essential part of healthcare. In Sri Lanka, pharmacy practice is less evolved than in Australia or some of its Asian neighbours. The major contribution of pharmacists to current practice in Sri Lanka is dispensing either in community pharmacies or hospital pharmacies. Currently, the majority of the hospital pharmacists have a proficiency (two years' graduate diploma) pharmacy qualification the rest have a bachelor degree. Many community pharmacists have a graduate certificate or graduate diplomas level vocational qualification. All of them are equally registered as pharmacists with the Sri Lanka Medical Council (SLMC). There are few pharmaceutical companies based in Sri Lanka, and only a small number of graduate pharmacists work in the formulation and production areas or drug regulatory authorities.

Pharmacy training was first introduced in Sri Lanka in the early 1950s. In 1957, a full-time pharmacy certificate course was introduced. Since then, three types of pharmacy certificates have been awarded; a vocational certificate of proficiency in pharmacy ( 6 mo), a vocational certificate of efficiency in pharmacy (6-12 mo), and a diploma of pharmacy (two years). A Bachelor of Science degree course commenced at the University of Colombo in 1999 offering the final two years of specialisation in Pharmacy. The Bachelor of Pharmacy (B Pharm) program was introduced in 2006 at the University of Peradeniya (UP) in the central part of Sri Lanka, the University of Sri Jayewardenepura (USJ) in Colombo, and in the Northern region at the University of Jaffna (UJ). Following that the University of Ruhuna (2010) at Galle in the Southern Province, the Open University of Sri Lanka (2013) in Colombo, and Kotelawala Defence University (2014) in Colombo have also started B Pharm degree programs [1-3]. To date, no local university is providing a postgraduate program in pharmacy. Currently, approximately 100 graduate pharmacists have been produced from local public universities. After secondary school year twelve examination (advanced-level examination), limited numbers of students secure scholarships to study a B Pharm nationally or a PharmD (Doctor of Pharmacy) overseas. The second international consultation on undergraduate medical and pharmacy education, health action international Asia-pacific concluded that: "In Sri Lanka, the practice of pharmacy is one of the neglected areas of health services and medical practice. Both community and hospital pharmacies are in a deplorable state and although official reports have made recommendations for their improvement, nothing has been done in this direction" [4]. The country is now establishing B Pharm programs at local public universities and many academic members of the pharmacy program have started their postgraduate studies in overseas universities researching in various fields such as pharmacy practice, community pharmacy, pharmaceutical technology, and pharmaceutical chemistry.

In 2010, the Ruhuna University B Pharm program was commenced as a program within the Faculty of Medicine with only 11 students. The program consists of a total of 120 credit units, in eight semesters over four years. Teaching includes lectures, laboratory practicums, clinical orientation programs at hospitals and community pharmacies, industrial visits, a final year research project and tutorials taught over eight semesters. The clinical pharmacy and pharmacotherapeutic course contents are allocated 9 credit units out of the 120 for the entire course. Pharmacy Practice and therapeutics-related topics are taught from the fifth semester (third year of the four-year course) onwards, this also included 260 h' clinical orientation program at the Teaching Hospital Karapitiya and Teaching Hospital Mahamodara Galle, Sri Lanka. Pharmacotherapeutic units are currently taught by medical practitioner academics, not pharmacist academics. Each credit is equivalent to 15-hours face-to-face lectures or $\geq 30 \mathrm{~h}$ of practical and clinical orientation programs. Students' performance at each clinical or pharmacotherapeutic unit examination is assessed and graded by a combination of methods including; clinical orientation evaluation, mini practical examination and oral examinations. When there are multiple examinations for a unit, marks obtained by the student are combined to obtain a final grade [5].

The current B Pharm program course at the University of Ruhuna is taught predominantly by academics with pharmacy, medical, chemistry and science backgrounds, including clinical pharmacology, but with no clinical pharmacy experience. Students 
had limited exposure to clinical placements during their undergraduate years. Clinical Pharmacy services are not yet developed in most of Sri Lanka. This may be partly due to professional isolation, a lack of qualified clinical pharmacists, and lack of recognition of the role of clinical pharmacists within the healthcare system [6]. The lack of experience and expertise amongst practitioners and academics in Sri Lanka has resulted in a relative inability to develop and deliver a rigorous and effective clinical pharmacy teaching program. There are no clinical pharmacy mentors, clinical tutors, or role models. The Sri Lankan pharmacy academics in Ruhuna University became concerned about this gap. The second author on this paper approached two Australian clinical pharmacists who were pharmacy academics at Charles Darwin University (CDU, at the time of writing this paper, now at University of Wolverhampton, UK), to collaborate in addressing this gap. Additionally, these two academics, supervised two of the academic staff at Ruhuna University to gain PhD's researching in disease management to empower them to teach clinical pharmacy.

In Australia, the Bachelor of Pharmacy degree ( 320 credit points in our system, 4-year program) is a clinically-oriented course that aims to produce graduates who are healthcare-focused, independent thinkers with clinically sound knowledge. The course prepares the graduate to work in any pharmacy setting. Graduates undertake a minimum of 10 $w^{\prime}$ placement during the undergraduate course followed by an additional $1860 \mathrm{~h}$ during their preregistration year. The B Pharm in Australia has a clear emphasis on clinical pharmacy, pharmacy practice, therapeutics, pharmacy calculations, multidisciplinary training, clinical placement, marinating strong foundation in basic sciences, pharmacology and pharmaceutics. Students also undertake a short research project in their final year. Pharmacy students are assessed through multiple methods including written, oral and practical assessments and must meet the national competency standards framework competencies for pre-registration by the end of their 4-year degree. They are then placed in either community or hospital pharmacy to complete their pre-registration year, undertaking additional oral and written examinations and a number of assessment items which include the quality use of medicine and health promotion projects. Starting from the pre-registration year, pharmacists in Australia must complete 40 credit points of continuous professional development to be able to register for the following year.

\section{The project}

The aim of this paper is to report on a clinical pharmacy and mental health first aid training program, delivered in 2015 to a fourth-year bachelor of pharmacy students from the University of Ruhuna and to train the staff to be able to teach the material independently in the future and is based upon student feedback.

\section{Ethics}

As advised by the Ethics Committees, no ethical clearance was required for the planned data collection as this was an educational program audit.

Two clinical academic pharmacists from Australia were invited to conduct a workshop on clinical pharmacy related topics for final year B Pharm students at the Faculty of Medicine, University of Ruhuna Sri Lanka. In these workshops, 24 students from two different intake cohorts; first batch $(\mathrm{n}=16)$ and second batch $(\mathrm{n}=8)$ could complete the three-day workshop on clinical pharmacy and a two-day workshop on mental health first aid. The workshops commenced with a one-hour conceptualization lecture followed by case study based workshops. Students were divided into teams of six. The different cases were distributed one per group, resources were provided for students use (e. g. Australian Medicines Handbook, the Society of Hospital Pharmacists' publication "Do not rush to crush", and Jeff Hughes' Use of Laboratory Test Data. Students were given one hour to discuss the case and complete their recommendations. At the end, each group presented the case and their findings and recommendations to the rest of the class. The following workshops were conducted:

\section{Clinical Pharmacokinetics}

Interpreting laboratory results

\section{Don't rush to crush}

Compatibility of medication with parenteral fluids

\section{Patient medication review}

The workshops were conducted in the students' usual class rooms. After completion of the workshop, students were asked to fill an anonymous feedback form that was collected using the standard university feedback form, with which they were familiar. The form evaluates the session content, delivery and relevance to the students. In addition, student's examination grades were also considered to evaluate the outcome of the two-day workshop.

The final two days were the mental health first aid course. The course is validated nationally in Australia and internationally in 21 countries. It is designed to provide the attendees with a deeper understanding of the issues that impact on and relate to people's mental health. It is designed to teach practical skills that can be used every day, including being able to identify the signs and symptoms of mental health issues and enable the first aider to feel confident in guiding people towards appropriate support. Independent research and evaluation show that MHFA course raises awareness and mental health literacy, reduces stigma around mental ill health and inculcates confidence in guiding people towards appropriate support. It also boosts knowledge and confidence in dealing with mental health issues, encourages people to start a conversation with a person who may be experiencing a mental health issue and promotes early intervention which may enable recovery. Considering that mental illness and the suicide rate is very high in Sri Lanka, this course with valuable to students on both professional and personal levels.

At the end of the two days, students completed an evaluation form, and they were registered in the MHFA Australia course webpage. The following day they received a link to the MHFA Australia to complete an online 16-question quiz after they achieved the $100 \%$ pass they received their competency certificate by email. The certificate is valid for three years and qualifies them as mental health first aiders.

\section{Evaluation of clinical pharmacy workshop}

There were total 24 students from two different batches $\left(4^{\text {th }}\right.$-year Semester 1 intake and Semester 2 intake) complete the three-day clinical pharmacy workshops. All students $(100 \%)$ completed the feedback forms (table 1). All the components in the evaluation form were rated well from the students and many positive comments were received from them.

\section{Comments written by participates}

The final question in the students' feedback form was "do you have any other comments?". Students' comments were analyzed thematically. The following were the common themes:

Words that implied positive students' experience: interesting, experience, important, happy

Terms that implied students' satisfaction: should continue, come again, improved, thank you, our society will have benefit, helpful to us, we will use the knowledge when we graduate, I am so happy

Words that described the students level of satisfaction: good, excellent, great work with us, very important, so happy

Terms will be used to inform future planning through the continuation of the parts students found useful and the improvement of the parts they found hard or challenging:
a. Delivering pattern was interesting-continue
b. Covered a wider area of knowledge about clinical pharmacy- continue
c. Important to organize such workshops annually-continue
d. Allocated time for workshop was limited-improve
e. Allocated time should be longer than this-improve
f. Content was high in limited time-improve 
From the overall personal comments from students, it appears that this program was felt to be essential for them and, they need this program to be continued in the future with a longer duration than five days. However, unless the program can free some academic time and contact, a longer period will not be possible.

As shown in table 1, from the students' feedback from results; more than $79 \%$ of the students responded positively for almost all the questions asked in the feedback form. All the respondents $(100 \%)$ said the material was relevant to their course need and its learning objectives. Most students rated the entire experience as being excellent (69\%) and good (29\%) with only $4 \%$ rated it as being satisfactory.

The end of semester assessment results appeared consistent with the students' feedback. However, as there was no previous data from past cohorts to compare with, so the results can only be used as the baseline for future years. Additionally, from the examination results, we can assume that the students had no difficulty learning the way others learn in Australia, in teams and from case-based learning rather than the didactic approach with which they were familiar with. From the 24 students who attended the workshop, 33\% of semester one entry batch achieved an "A" (80-89 marks), 17\% of students achieved an A-(75-79 marks) and 50\% of students achieved B+ (70-74 marks) in their final clinical pharmacy module examination. Whereas among semester two entry batch, who attended the workshop, $33.3 \%$ of them obtained A-, 33.3\% obtained B+ and 33.3\% achieved B (65-69\% marks) in their semester Hospital and Clinical Pharmacy module. Notably, students who did not attend or could not complete the entire five-day workshops achieved B+ or less in the assessment.

Three academics and two technical staff from Ruhuna University were involved in the workshops either to take part (as train the trainer) or as staff running the activities with the Australian academics. This was professionally satisfying for all academics and technical staff where the exchange of techniques in learning and teaching and cultural awareness took place.

While pharmacists in Sri Lanka were perceived to be the specialist in dispensing prescriptions and supplying of medications, the scope of pharmacy practice is much broader [4]. Pharmacist clinical services are well established in the hospital setting and growing rapidly in community settings [7-8]. Clinical pharmacy is the pharmaceutical care services concerned with the science and practice of rational use of medicine and the discipline in which pharmacists ensure the safe and quality used of medicine, promoting patient adherence to their therapy, their health literacy and self-management skills and lifestyle modification to improve their health outcomes [9]. The pharmacist is an active member of the primary health care, where clinical pharmacists provide pharmaceutical care that is based on sound therapeutic knowledge, experience and professional judgment [9]. Clinical pharmacy contributes to improving patient awareness of their medication in relation to their condition and lifestyle, aiming to improve health and quality of life [8].

Clinical pharmacists can review a patient's medications to optimize therapeutic outcomes while reducing the number of medication used, reducing the overall experienced side effects and improving adherence and medication safety [7].

During undergraduate pharmacy courses through case-studies and problem-based learning students, develop the skills of clinical pharmacy in a safe environment where they can be mentored or coached until they establish their own style of patient approach, assessment and then assisting with the clinical intervention [10-11].

Students' feedback showed that workshop style for learning was better perceived by them and more suitable for learning aspects of clinical pharmacy and developing clinical skills such as interpreting laboratory results, review patient medications, optimize medication use and provide mental health first aid than class room lecture style.

Table 1: Evaluation and feedback from students $\mathrm{N}=\mathbf{2 4}$

\begin{tabular}{|c|c|c|c|c|c|}
\hline & $\begin{array}{l}\text { Strongly agree } \\
\text { Frequency } \\
(\%)\end{array}$ & $\begin{array}{l}\text { Agree } \\
\text { Frequency } \\
(\%) \\
\end{array}$ & $\begin{array}{l}\text { No opinion } \\
\text { frequency } \\
(\%)\end{array}$ & $\begin{array}{l}\text { Disagree } \\
\text { frequency } \\
(\%) \\
\end{array}$ & $\begin{array}{l}\text { Strongly disagree } \\
\text { frequency } \\
(\%)\end{array}$ \\
\hline Started the lecture on time & $16(67)$ & $8(33)$ & & & \\
\hline Lecture was well prepared & $20(83)$ & $4(17)$ & & & \\
\hline $\begin{array}{l}\text { Displayed clearly projected materials (Power } \\
\text { point slides) }\end{array}$ & $16(67)$ & $7(29)$ & & $1(4)$ & \\
\hline Lectures were clear and understandable & $9(38)$ & $14(58)$ & $1(4)$ & & \\
\hline Presented materials in a well-organised way & $13(54)$ & $10(42)$ & & $1(4)$ & \\
\hline Stressed important points & $12(50)$ & $10(42)$ & $1(4)$ & $1(4)$ & \\
\hline Delivered the lecture on right speed & $6(25)$ & $14(58)$ & $3(13)$ & $1(4)$ & \\
\hline Encouraged students to ask questions & $18(75)$ & $6(25)$ & & & \\
\hline $\begin{array}{l}\text { Indicated the relevance of lecture material to } \\
\text { clinical work }\end{array}$ & $17(71)$ & $7(29)$ & & & \\
\hline Could be clearly heard & $9(38)$ & $12(50)$ & $3(13)$ & & \\
\hline Made me sleepy most of the time & & $3(13)$ & $2(8)$ & $14(58)$ & $5(21)$ \\
\hline Made it easy for note taking & $1(4)$ & $14(59)$ & 7 (29) & $1(4)$ & $1(4)$ \\
\hline Lecture was too slow & $2(8)$ & $2(8)$ & $1(4)$ & $12(50)$ & $7(29)$ \\
\hline Made lectures interesting & $13(54)$ & $11(46)$ & & & \\
\hline \multirow[t]{2}{*}{ Summarized the lecture at the end } & $8(33)$ & $14(59)$ & $2(8)$ & & \\
\hline & $\begin{array}{l}\text { Extremely } \\
\text { important }\end{array}$ & Very important & Important & Useless & Waste of time \\
\hline \multirow[t]{2}{*}{ Do you think this questionnaire is } & $15(53)$ & $6(25)$ & $3(12)$ & & \\
\hline & Excellent & Good & Satisfactory & Poor & Very poor \\
\hline My overall impression about the workshop & $16(67)$ & $7(29)$ & $1(4)$ & & \\
\hline
\end{tabular}

\section{CONCLUSION}

Learning clinical pharmacy as a team through case-based style taught by practicing clinical pharmacists enabled the undergraduate pharmacy students from Ruhuna University to learn and apply new skills in a safe environment during workshops and perform satisfactorily in their examination.

The collaboration between Australian and Sri Lankan academics was a great benefit for both parties. There is an intention to continue the collaboration and continue to improve the quality of teaching and learning experience.

\section{LIMITATION}

The main limitation was the limited provided resources, as students had to share the few copies of reference materials to keep the cost within budget. Additionally, providing some light food and drinks could improve the student concentration and energy, however, the budget did not allow that either. 


\section{CONFLICT OF INTERESTS}

Declare none

\section{REFERENCES}

1. ID Coombes. Collaborating to develop clinical pharmacy teaching in Sri Lanka. Int J Pharm Edu 2013;13:23-35.

2. SLMC. Pharmacology courses in Sri Lanka; 2011.

3. Shukry Zawahir, Dhakshila Niyangoda, N Lakmali. Pharmacy practice in developing countries. Achievements and Challenges in Pharmacy Practice in Developing Countries. Achievements, Challenges, Ahmed Ibrahim Fathelrahman, Mohamed Izham Mohamed Ibrahim, AI Wertheimer. Editors. Elsevier; 2016. p. 475.

4. Anon, Undergraduate medical and pharmacy education, in the need for change and the way forward. Second international consultation on undergraduate medical and pharmacy education, health action international Asia-Pacific; 2005. p. 1-13.

5. The University of Ruhuna, Student Handbook, Bachelor of Pharmacy. Vol. 1. Faculty of Medicine, University of Ruhuna Sri Lanka; 2010.
6. S Anderson. The state of the world's pharmacy: a portrait of the pharmacy profession. J Inter Prof Care 2002;16:391-404.

7. H Morrissey, PA Ball, DM Jackson, LSJ Pilotto. Community pharmacists' intervention: how a 6-episode of one-on-one intervention changed patient's attitudes towards their medication and disease self-management. Int J Pharm 2014;4:5-13.

8. H Morrissey, PA Ball, DM Jackson, LSJ Pilotto. Use of chronic disease management algorithms in Australian community pharmacies. Res Soc Administrative Pharm 2015;11:176-96.

9. PA Ball, AK Davey, JP Shaw. Eds. From Clinical Pharmacy to Pharmaceutical Care. Aukland, Medimedia; 2004. p. 223.

10. H Morrissey, PA Ball. Pharmacy subjects' development. Currents in Pharmacy Teaching and Learning; 2014. Available from: http://dx.doi.org/10.1016/j.cptl.2014.05.016. [Last accessed on 10 Dec 2017]

11. H Morrissey, P Ball. Training evaluation reports reflection on teaching strategies for pharmacy. Journal of Pharmacy Education; 2016. 